\title{
Organización y poder en la CEDA gallega
}

\author{
Emilio Grandio SeOane*
}

\section{RESUMEN}

Uno de los movimientos políticos menos estudiados en Galicia durante

el primer tercio del siglo $x x$ es el conservadurismo. La proclamación de

la I/ República supuso el cambio inmediato de poder en las instituciones

oficiales. Pero la mayoría de las organizaciones politicas mantenían su tradicional modelo de funcionamiento. El sistema democrático creado durante

la II República duró escasamente cinco años, un corto período comparado con los cincuenta de la Restauración Borbónica. Los sectores regionales conservadores se inclinaron por mantener aquellos modos politicos que habian estado practicado durante estos cincuenta años. Del mismo modo que la Monarquía, el Catolicismo era considerado por la derecha gallega como algo propio de las tradiciones españolas. La designación de la organización gallega con el nombre de "Unión Regional de

\begin{abstract}
One among the less known political movements which developed in Galicia during the first third of the 20th century is the conservative one. The proclamation of II Republic implied an immediate change in the sphere of the oficial institucions. But most political organizations kept their traditional way of functionning. The democratic system created during the II Republic lasted merely five years, a short period when compared with the fifty years covered by the Bourbonic Restauration system. Conservative-oriented regional were inclined to keep making politics as they had being doing for fifty years.

Like the monarchy, Catholicism was seen by the Galician right as something characteristic of Spanish tradition. The designation of the Galician party with the name of "Regional Right Union" (U.R.D.) was a clear symbol of this attempt to offer an image of conservative, but at the
\end{abstract}

* Universidade de Santiago de Compostela. 
Derechas" (U.R.D.) fue un claro símbolo de este intento de ofrecer una imagen conservadora y al mismo tiempo de partido moderno. La creación de nuevas organizaciones locales estaba totalmente dirigido por

el comité madrileño de "Acción

Popular". La prueba de que los dirigentes de la URD abandonaron la opción democrática tras la derrota electoral de Febrero de 1936 fue el silencio absoluto mantenido por el aparato del partido.

PALABRAS CLAVE Galicia. 1931-1936. Relaciones de poder. CEDA. Organización local. same time modern party, using some regionalist slogans in its political message. The proof that URD leaders gave up any allegiance to democracy after their electoral defeat in February 1936 was the absolute silence kept by the organisation.

\section{KEY WORDS}

Galicia. 1931-1936. Power relations. CEDA. Local Organization.

\section{POLITICA Y RELIGIÓN EN LOS PRIMEROS AÑOS DE LA II REPÚBLICA EN GALICIA. LA REACCIÓN DEL CATOLICISMO SOCIAL: LA UNIÓN REGIONAL DE DERECHAS}

Sin lugar a dudas el partido que hegemonizó las orientaciones conservadoras y de derechas durante la II República fue la CEDA. Como partido protagonista de la evolución política del régimen republicano, ha sido tratado en profundidad, sobre todo en sus apartados ideológicos y de organización. Sin embargo, existen notables carencias en cuanto a los procesos de implantación de la organización cedista en los distintos territorios. Además, su pretensión manifiesta de conformar una "Confederación» de las organizaciones de carácter conservador del Estado destaca esta insuficiencia de estudios al respecto.

Este planteamiento se hace necesario cuando se observan las claras diferencias que existen entre el apartado teórico y la práctica política del partido. Javier Tusell considera que es muy difícil delimitar totalmente el "corpus ideológico" de la CEDA, precisamente por el elevado grado de ambigüedad de su discurso. José Ramón Montero y Paul Preston explican esta característica de la organización por su afán de controlar el Poder por vía legal, sacrificando ciertas cuestiones que no 
se presumian necesarias para sus posibles votantes, pero que se tornaban en determinantes para continuar en el juego político republicano, como la consideración «accidentalista» del sistema en el que participaron ".

Durante el primer tercio de nuestro siglo en el Estado español, la institucionalización del nuevo sistema republicano provocaba en la mayor parte de las elites familiares del sistema turnista cierta expectación. En otros casos lo que se producía era un profundo rechazo, sobre todo al recordar la fallida experiencia de la I República. Pero las circunstancias habían cambiado notablemente en los sesenta años que separaban una y otra experiencia republicana. Entre otras circunstancias era innegable el hecho de que gran parte de la sociedad española, gracias a la difusión de los medios de comunicación y la influencia de sus mensajes en las masas, se había situado al margen de la representatividad institucional que en aquellos años tenía el Parlamento, organizándose en partidos obreros y republicanos.

En Galicia las circunstancias que provocaron la instauración del nuevo sistema político fueron idénticas al resto del Estado. Estas fueron impulsadas fundamentalmente desde la ciudad de A Coruña, auténtico núcleo rector del republicanismo gallego, que se había cimentado tras varios años de mayorías políticas de este signo en el gobierno municipal. Abad Conde, en el radicalismo de Lerroux, y Casares Quiroga, dentro de la izquierda progresista, fueron las dos figuras que se presentaban de salida como las más influyentes dentro del nuevo sistema. De hecho, los dos ejercieron su carrera política durante la II República en los círculos centrales del poder, tradicional aspiración del político gallego.

Frente al republicanismo creciente, la situación de la derecha en Galicia distaba mucho de ser una situación idílica. La paralización casi absoluta de la política nacional en los primeros años del siglo xx provocó la escasa confrontación de ideas, dentro de un sistema que no olvidemos había sido creado para paliar una situación de inestabilidad social. El hecho de conseguir un escaño en base a la representatividad popular era siempre visto a través de la posibilidad de realizar desde su persona variados procedimientos de fraude. De ahí el hecho de la reacción visceral que más de treinta años de prepotencia política habían creado ante lo que se situaba fuera del sistema: la República.

TuSELl, J.; Historia de la democracia cristiana en España, Sarpe, Madrid, 1986, 2 vols.; Montero Gibert, J.R.; La CEDA, el catolicismo social y político en la II República, Revista del Trabajo, Madrid, 1977, 2 vols.; Preston, P.; La destrucción de la democracia en España, Alianza, Madrid, 1987. 
El propósito fundamental de este trabajo es intentar mostrar la conversión de los sectores de la derecha gallega de la Restauración a través de la estructuración local de un partido que acaparó prácticamente todo el espacio de la derecha durante la II República: la Unión Regional de Derechas / CEDA. El mensaje ofrecido por esta organización como una agrupación de partídos conservadores y regionalistas resulta, cuando menos en el caso gallego, excesivamente pretencioso, sobre todo cuando analizamos su estructura local, sus modos de relación interna y su jerarquía de poder.

Durante los años finales de la Restauración y la Dictadura de Primo de Rivera las elites familiares que detentaban el poder político se daban cuenta del problema de representatividad que se estaba produciendo en el seno mismo de la sociedad ${ }^{2}$. Aún sin perder sus influencias clientelares, apostaron por una visión más abierta, llevando consigo todas sus relaciones en beneficio de unas nuevas siglas. En los primeros momentos estas relaciones se establecieron fundamentalmente o con el radicalismo ya moderado de Lerroux, o con el progresismo dotado de ciertos matices galleguistas de la Organización Republicana Gallega Autónoma (ORGA), verdadero gestor del cambio político en Galicia ${ }^{3}$. Como ejemplo de este dominio político podemos decir que antes de acabar 1931 el $84 \%$ de los municipios de la provincia coruñesa eran controlados por miembros de la coalición política gobernante del primer bienio, muy especialmente de corporaciones de ORGA, que tenían el 70\% de los Ayuntamientos, incluyendo los municipios de Coruña y Santiago ${ }^{4}$.

La verdad es que la jerarquía católica gallega no se había sentido necesitada de formar un partido político para defender sus intereses hasta que observó el rumbo que tomaba la nueva Constitución de 1931. La intención de los republicanos y socialistas de crear un nuevo Estado

2 La especificación "elite política" es más limitada que el concepto de clase política. A ésta pertenecen todos los políticos en la medida en que participan de la estructura de privilegios, incluso aunque no alcancen una gran importancia en la jerarquia decisoria de la élite; KLAUS VON BEYME; La clase politica en el Estado de partidos, Alianza, Madrid, 1995, pág. 30.

3 Este proceso de adaptación de las clientelas locales al republicanismo se encuentra muy bien estudiado en Lamela Gafcía, Pepe Miñones: Un crimen en la leyenda (1900-1936), Ediciós do Castro, A Coruña, 1991

4 A partir de este momento la ORGA, a través de sus redes políticas locales, se convirtió en la organización dominadora de la política provincial en este período, y aún en 1935. después de la suspensión de los partidos de izquierdas, la sección gallega de "zquierda Republicana" tenía mayoría en un tercio de los municipios de la provincia; ver GRandio, E; “O poder local na provincia da Coruña durante a II República", en Poder local, elites e cambio social na Galicia non urbana (1874-1936), Universidade de Santiago, 1997, págs. 243-274. 
completamente laico chocaba con la férrea disposición de una Iglesia que en su mentalidad aún no había pasado del siglo xix, y que no observaba con gran intención de colaborar dentro de un proyecto que intentaba ser resultado del consenso de todos los españoles, pero que al mismo tiempo establecía fuera del sistema a ciertas órdenes religiosas como los Jesuitas.

La jerarquia gallega en su totalidad se encontraba ideológicamente frente a estas nuevas medidas, sobre todo tras el amargo sabor que les había dejado el hecho de que el movimiento republicano era aquel que había colocado fuera de la escena a uno de sus pilares ideológicos: la Monarquía. Esta imbricación en el pensamiento religioso entre liturgia y esfera civil provocaba que cualquier actuación política fuera considerada dentro de los palacios episcopales como un ataque contra la propia religión, contra Dios, dentro de una mentalidad en la que sólo existían dos términos: O nosotros $y$ el Bien, o todo lo que no se encuentra con nosotros y el Mal ${ }^{5}$.

Pero la autentica realidad era que la Iglesia gallega, tras la primera década de siglo, comenzaba a tomar sus precauciones ante el avance de las sociedades políticas obreras, difundiendo la creación del movimiento de $A c^{-}$ ción Católica en las ciudades, y de los sindicatos agrarios confesionales, espacio en donde el mensaje obrerista aún no había calado muy hondo, orientado de manera preferente hacia grandes unidades de población. El rural gallego sería el espacio en donde encajaría mejor el mensaje del asociacionismo católico, en un mundo en donde el universo social quedaba prácticamente reducido hasta la montaña más próxima, y en donde se establecía una relación muy estrecha con el sacerdote de la parroquia correspondiente. Cualquier intento de establecer un sindicato de ayuda a la labor agrícola en estas tierras era bien visto por la Iglesia local, deseosa de seguir ostentando desde su posición de "consiliario" de la naciente sociedad un poder consultivo importante en la comunidad local. Esta situación de privilegio en el campo, a la llegada de la II República sería aprovechada convenientemente por la Unión Regional de Derechas (URD).

Las primeras noticias que tenemos respecto a la creación de este partido nos remiten a las primeras reuniones que mantuvieron en Madrid los creadores de Acción Nacional, núcleo fundacional de lo que posteriormente se llamaría por imperativos legales Acción Popular, y posteriormente, Confederación Española de Derechas Autónomas (CEDA). A

s Muy documentado en el trabajo de Carballo, F.- Magarinos, Alfonso, La lglesia en la Galicia contemporánea. Análisis histórico y teológico del periodo 1931-1936, II República, Akal, Madrid, 1978. 
pesar de la inexistencia de una amplia gama de estudios locales sobre este partido en España, podemos afirmar que a excepción de láa organización madrileña, de ciertas provincias castellanas y del nuevo partido de masas de la Derecha Regional Valenciana, es en Galicia en donde se continua el proceso de fundación, con la creación de Acción Nacional. Precisamente se crea en aquella ciudad en donde la Iglesia gallega se encontraba mas representada y dotada de mayor influencia, en Santiago de Compostela, no casualmente la ciudad que llevó el mando de la nueva organización confesional hasta el fin de la II República.

Presentó su reglamento al Gobierno Civil de A Coruña el 18 de junio de 1931, pocos días antes de la nueva convocatoria electoral, pero sin intención de acudir a ella, ya que sus pretensiones eran las de crear un proyecto más amplio ${ }^{6}$. Resulta curiosa la inscripción de este reglamento ya que al margen de las especificidades propias de su ubicación en la capital gallega, todos los demás artículos son calcados íntegramente del presentado por Acción Nacional de Madrid el 29 de abril de ese mismo año, notificando incluso la dirección del centro social madrileño en el número 3 de la Plaza de las Cortes. Esta relación tan estrecha se debe sin duda a los contactos establecidos entre los dirigentes madrileños y el Catedrático de Derecho Político de la Universidad compostelana, Carlos Ruiz del Castillo, quién después de pertenecer a principios de los años veinte al intento social-demócrata del Partido Social Popular consiguió hacerse con la Cátedra en la Facultad de Santiago ${ }^{\text {bis }}$. Este, junto a otros tres claros exponentes de la "religiosa» sociedad compostelana, como el industrial Ricardo Bermejo Pena, el arquitecto López de Rego y el dirigente de asociaciones religiosas Julián Pérez Esteso, fueron los cuatro firmantes que presentan al Gobierno Civil esta nueva asociación, que no tenía en los primeros momentos ninguna intención de distinguirse para nada de la central madrileña.

Si bien se creó la sección compostelana de Acción Nacional, la auténtica realidad fue que sus efectos en la sociedad gallega fueron nulos, ya que no se celebraron actos de propaganda después de su constitución. Y es que esta elite política derechista local se encontraba preparando un proyecto de futuro, que enlazaría directamente con los realizados en otros lugares del Estado. De este modo, el 20 de noviembre de este año se presenta otro reglamento, esta vez con el nombre definitivo

Archivo del Reino de Galicia, Fondo Gobierno Civil, legajo 2563

6b:s La presencia de Carlos Ruiz del Castillo en Santiago fue determinante, no sólo desde el punto de vista organizativo sino también ideológico; ver GRANDiO, E.: "Dereita e rexionalismo galego no Il República: Carlos Ruiz del Castillo", Grial, n. ${ }^{\circ} 134$, abril-Xuño, 1997, págs. 185-217. 
de Unión Regional de Derechas (URD). Este traía ya un mayor apoyo en adhesiones, ya que aparte de las cuatro anteriores contaba con la firma, entre otros, del Presidente de la Cámara de Comercio local, Francisco Porto, o el dirigente de los sindicatos agrarios católicos, Jacobo Varela de Limia ?. Este ya no era el proyecto de cuatro dirigentes católicos aislados, sino que nacía con la pretensión de convertirse en el nuevo partido hegemónico de las derechas gallegas. Es innegable la influencia de la estructura de partido de la Derecha Regional Valenciana, ya que no hay que olvidarse de su denominación —no por casualidad- de Unión Regional de Derechas, cuyo modelo de partido de masas serviría para estructurar y dar forma a una nueva organización política.

La esencia del nuevo partido era idéntica a la que se recogía en el primer reglamento de Acción Nacional, pero lo que ha cambiado en sus promotores ha sido el modo en que se realizaba este proyecto. Ya no se partía de la actitud individual de cuatro personas sin especificar cargos en la Junta Directiva, sino que este último reglamento ya había sido aprobado en una Junta General fundacional efectuada el 13 de noviembre. Contaba con la división de funciones en cuatro comisiones especializadas (Hacienda, Propaganda, Electoral, Organización social y agraria), cada una de ellas integrada por cinco miembros y dirigidas a su vez por un Presidente y un Secretario. Las bases del nuevo partido se habían puesto en marcha. Aunque la construcción del mismo seguía siendo una incógnita, sus ansias de conseguir un proyecto político perdurable y al margen de los distintos sistemas de gobierno paliaron en parte una débil estructura organizativa.

\section{LA CREACIÓN DEL NUEVO PARTIDO. EL CAMINO HACIA UNA NUEVA REPRESENTATIVIDAD EN LAS URNAS}

La verdad fue que el nuevo partido cuajó de una manera asombrosa incluso para sus propios promotores. Antes de acabar este año de 1931, en apenas mes y medio, se crearon y fundaron en Galicia cinco organizaciones locales dependientes todas ellas de la central de Santiago. Estas en su mayor parte se encontraban localizadas en la provincia coruñesa: Juventud de Unión Regional de Derechas y Coalición Regional de Derechas Democráticas en A Coruña, Derecha Regional Gallega de Ferrol, Unión Regional de Derechas de Pontevedra, y Acción Popular de Ourense.

A.R.G., F.G.C., leg. 2.563. 
Parecía como si el votante gallego necesitara la instalación de estas asociaciones confesionales, como si se echaran en falta y bastara un pequeño apoyo para que surgieran de la nada. El hecho fue que el proceso de creación fue extremadamente rápido para el tradicional nivel de participación política que caracteriza a Galicia. En buena parte se realizó de este modo por la conexión profunda que desde hacia unos cuantos años se habia formado en el rural gallego entre el sentimiento tradicional religioso y la participación en política. No es casual que entre los años de 1932 y 1933 se crearan 91 organizaciones de URD o AP en las cuatro provincias gallegas, cerca del $70 \%$ del total de organizaciones registradas durante la República. A ello se añade el hecho de que muchas de ellas se fundaron en lugares donde la única voz del exterior de la comunidad local podía llegar, bien por los círculos sociales establecidos de esta sociedad o a través de la Iglesia, de su respectivo párroco.

El proceso de expansión y difusión del partido fue protagonizado casi exclusivamente por los dirigentes y propagandistas de Santiago, bien por medio de oradores "curtidos" como Gil Casares y Jacobo Varela de Límia, o por jóvenes procedentes en su mayor parte de las organizaciones confesionales escolares, fundamentalmente de la Facultad de Derecho, que hacían sus primeras tablas en política dirigiéndose desde la provincia coruñesa a los locales de Lugo y Pontevedra ${ }^{8}$. Esta última, junto a la coruñesa, fueron las dos provincias en donde la difusión de la propaganda cuajó de una manera más rápida, asimilando el hecho de que la derecha política debía de cambiar de mentalidad para conseguir mayores fines que la consecución de un simple escaño, el conseguido por Blanco Rajoy en la circunscripción coruñesa en junio de 1931. En torno a estos propagandistas compostelanos se configurará el mayor partido de derechas conocido en Galicia hasta ese momento, estructurando una organización política, aún a costa, como relataremos posteriormente, de perder ciertas cotas de autonomia en beneficio de un mayor poder real.

La conjunción de estos objetivos presumía la existencia de un órgano supremo de poder como era la Asamblea Regional, reunión que se celebraría en Santiago entre los días 4 y 6 de febrero del año de 1933, con la asistencia del lider nacional Gil Robles, y que tenía el carácter de reunión preparatoria de lo que iba a ser la futura Asamblea Fundacional de la Con-

\& Existe una relación muy estrecha entre los dirigentes cedistas y la ACNP, hasta el punto de que hombres como Gll Perez, Pérez Esteso, Cándido Varela de limia, Fermín Zelada de Andrés Moreno, Maximinc Romero lema o Antonio Asorey Andaluz se encontraban en puestos importantes del grupo de élite de la jerarquía eclesiástica. 
federación Española de Derechas Autónomas (CEDA), que se celebraran en los primeros dias del siguiente mes de marzo ${ }^{9}$. A estas alturas, la Unión Regional de Derechas poseía ya la suficiente infraestructura como para organizar un evento de estas características, reuniendo en estos días a 180 representantes de más de 50 centros de URD de toda Galicia. Se encontraban ampliamente representados los delegados de las siete ciudades más populosas: Santiago, A Coruña, Ferrol, Pontevedra, Vigo, Ourense y Lugo.

Santiago era la única ciudad en estos momentos que tenía que ser necesariamente el centro de la derecha política en Galicia, debido a la gran labor emprendida por los integrantes de la organización cedista y sobre todo por su papel de enlace con la organización central de Madrid durante todo el período republicano. Buena prueba de la confianza del comité central en su labor es el hecho de que de las diez ponencias presentadas en esta Asamblea, seis de ellas fueron recibidas directamente de Madrid, sin alteración. Todas ellas, sin excepción, fueron explicadas por hombres y mujeres de la organización compostelana ${ }^{10}$.

Las restantes fueron llevadas a cabo por miembros de Lugo, Pontevedra y Vigo, al margen de la realizada por el Catedrático compostelano Carlos Ruiz del Castillo. Esta última fue la más importante de cuantas se presentaron a la Asamblea. Con base en su especialidad profesional (Derecho Político) Ruiz del Castillo expresa su propia visión de lo que debía ser la nueva fórmula de federación nacional de las derechas, que se tomaría muy en cuenta en la reunión nacional del mes siguiente.

Titulada Confederación o fórmula de inteligencia para federar las Derechas españolas, en esta ponencia se explicaba su opinión al respecto a través del proceso organizativo de la URD. Se destacaba el hecho de que Galicia habia sido la única región en donde no había existido hasta esta fecha ninguna discrepancia entre las diversas orientaciones personalistas del partido. Así explicaba Ruiz del Castillo cómo había sido el modo en que se había verificado esta unión de intereses:

No se ha encontrado sino un camino eficaz: no hablar públicamente de lo que pueda dividir. Con esto no trata de restarse importancia a lo que divide, sino de fortalecer lo que vincula. Lo que divide no se soslaya como accidente, sino que se supedita a la realización de objetivos concretos y urgentes, que encuentran bien dispuestos a los espíritus.

"El Ideal Gallego", del 4 al 7 de febrero de 1933.

"El Ideal Gallego", a 2 de febrero de 1933. 
Desde la consideración de una posición de privilegio, la URD, en boca de su representante más competente para cuestiones de índole estructural, afirmaba la necesidad de un poder central fuerte para la consecución de su objetivo más inmediato: una buena representación electoral. Las distintas tendencias del partido acordaron difundir en el discurso de la nueva organización aquellas circunstancias que les unian, y no resolver internamente sobre lo que les separaba. El mayor o menor barniz galleguista era una de aquellas cuestiones que alejaba las posiciones de consenso de la organización. Según Ruiz del Castillo, este fue el espíritu que impulsó a las organizaciones de la CEDA en las elecciones de noviembre de 1933:

No cabe, por ejemplo, pensar en una acción electoral conjunta si no existe un órgano común para concertarla y dirigirla. Todos convendrán en que no puede dejarse a la apreciación de las organizaciones locales el pacto de una alianza, que debe tener carácter nacional en la extensión y carácter permanente en el tiempo (siempre en el supuesto que plantean las actuales exigencias). Hay que velar, pues, por el mantenimiento de una disciplina, que requiere coordinación en los que dirigen y obediencia en los dirigidos ${ }^{11}$.

Si por algo se destacaba la URD del resto de las derechas españolas era en una imagen de organización sólida, además de la rapidez en conseguir esta situación privilegiada en un terreno ya de por sí difícil para la comunicación y para la relación política. Cada jerarquía local delegaba sus funciones, siempre de manera controlada, en aquellas personalidades que estuvieran más especializadas en ello. Por ejemplo, la cuestión agraria, siempre importante en esta región, fue abordada en esta Asamblea Regional por Jacobo Varela de Límia, que contaba con una gran trayectoria dentro de los sindicatos agrarios gallegos, pero también por representantes de las pequeñas "vilas» de Lalín, Cambados y Golada, inmersos en la problemática actual del agro.

Si tan sorprendente era esta delegación para los representantes de la derecha gallega, mucho más lo era el hecho de la no asistencia de un sólo sacerdote a la celebración de esta Asamblea, acostumbrada como estaba la opinión gallega a la presencia del clero en todos los actos políticos de carácter derechista. La intención propagandística de esta circunstancia era evidente: dar un nuevo giro a la tradición de la derecha, a las costumbres del personalismo clientelar. Ofrecer al electorado de derechas

Este texto y el anterior proceden de E.I.G., a 8 de febrero de 1933. 
una imagen limpia y moderna, con plena consciencia del mensaje que se le mostraba.

No casualmente Gil Robles comparaba la organización gallega con la valenciana de la DRV, ejemplo constante y pauta de conducta en la naciente organización nacional derechista. $Y$ es que el ejemplo organizativo de la Asamblea Gallega fue insospechado incluso para muchos de los comentaristas políticos de la época. En un artículo editorial del periódico «El Ideal Gallego", se asombraban de la gran capacidad de estructuración interna de la URD que se había demostrado en poco más de un año, desde diciembre de 1931 a febrero de 1933:

El resumen nuestro lo condensamos en una frase brevísima. Aquí hay organización. Y la organización es la base de la victoria en política como en todo; pero acaso más en política ${ }^{12}$.

El crédito y la confianza obtenida en la buena labor de esta Asamblea Regional de la URD fue suficiente para cambiar la posición reticente de buena parte de las clases medias gallegas hacia este partido. Su organización, sus ganas de trabajar en política desde una posición conservadora..., todo ello era pregonado por sus oradores en su discurso en un volumen superior a lo que era el programa concreto de los conservadores. Su objetivo era vender un producto a medio plazo, sin prisa pero sin pausa.

\section{LA DIVISIÓN DE LA LÍNEA ÚNICA. LA APARICIÓN DE DISCREPANCIAS}

La convocatoria anticipada de elecciones de diputados a Cortes para el mes de noviembre de 1933 cogió al partido en una intensa campaña de propaganda. Esta fue aprovechada para continuar y retomar la oportunidad perdida de dos años antes. Su organización electoral para estos comicios cabe calificarla de perfecta, sobre todo en aquellas zonas que controlaba directamente la asociación compostelana.

Al analizar los procesos electorales de la II República en Galicia es importante tener presente el fuerte grado localista de los candidatos cedistas, carácter que, por otra parte, también es común a otras listas. En el caso concreto que nos ocupa la importancia e influencia local de los

E.I.G., a 5 de febrero de 1933. 
representantes es tan fuerte, que en aquellas circunscripciones provinciales en las que la organización contaba con una presencia organizativa relevante, como la de $A$ Coruña, los puestos se repartían atendiendo a la representación zonal. De hecho de los siete candidatos que tenía la URD en la lista provincial coruñesa de derechas para las elecciones de noviembre de 1933, la zona de la capital contaba con tres candidatos (Blanco Rajoy, Méndez Gil Brandón y Vázquez Gundín), dos de Santiago (Gil Casares y Portal Fradejas) y uno de Ferrol (Pérez Barreiro) y Betanzos (Sánchez Valeiro) ${ }^{13}$.

Sus resultados finales fueron sorprendentes ya que la URD, presentada ahora como la CEDA gallega, obtuvo 10 escaños en las cuatro circunscripciones gallegas, quedando en segundo lugar detrás del Partido Radical, que obtuvo 15 escaños. La CEDA fue presentada como la gran vencedora en Galicia de unas elecciones en las que dentro de estas candidaturas derechistas, que consiguieron en su mayor parte escaños por las mayorías, iban además gran cantidad de hombres independientes, monárquicos o de Renovación Española, siempre a remolque del voto cedista, especialmente en la provincia de A Coruña ${ }^{14}$.

Conseguida ya una representación importante en Cortes, respaldada por una votación generalizada en el Estado, la Unión Regional de Derechas como tal organización se dispone a diferenciar el comportamiento de sus distintos niveles jerárquicos. Los diputados cedistas gallegos participan en mucho del carácter localista de su elección, al estilo del antiguo sistema canovista. La mayoría de los integrantes del grupo gallego de la Minoría Popular Agraria bien se ocuparon durante esta legislatura de realizar gestiones relativas del propio partido, o bien trasladaban al Parlamento peticiones muy particulares, como los casos de los diputados por la provincia de Pontevedra Guisasola y Lís Quibén, que se ocupaban por ejemplo de un tema de colocación familiar o del traslado de un Batallón de Ametralladoras a la villa de Tui, o el del diputado por Lugo, Ángel López Pérez, intentando defender la ganadería provincial lucense ante la competencia de la carne congelada procedente de Uruguay, cuando los perjuicios de este Tratado eran extensibles a las cuatro provincias gallegas.

No hubo prácticamente cambios en la designación zonal de estos candidatos para las elecciones de febrero de 1936, con la única excepción de la ausencia de Portal Fradejas, al corres. ponderle para esta elección a la CEDA únicamente seis puestos de los trece de la candidatura derechista por las mayorias.

Para observar el proceso de trasvase de votos entre las elecciones de 1933 y 1936 , ver Emilio Grandio, "Movilidad del voto en la provincia de La Coruña en la II República", Revista del Centro de Estudios Repúblicanos, abril-94, págs. 37-56 
Únicamente se escapaban a esta dinámica el diputado pontevedrés Barros de Lis -en contadas ocasiones-, y sobre todo, el Registrador de la Propiedad Eugenio Vázquez Gundín. De este último se puede decir que fue el único cedista gallego que promovió la discusión parlamentaria desde su propio interés y preocupación, más que desde la disciplina de partido. Podríamos caracterizarlo como descendiente directo del personalismo en la política pero, sin embargo, su carácter galleguista y su experiencia en los problemas rurales a través de su continua labor como dirigente de la Federación Católico-Agraria coruñesa, le obligaban a defender sus posiciones como representante directo de una votación popular. Aún siendo el último representante cedista elegido en esta provincia, quería ejercer este carácter de buen grado ${ }^{15}$.

Vázquez Gundín en los dos años que se mantuvo en el Parlamento ya que aunque también se presentó en 1936 no volvió a ser elegido- expuso en esta cámara una cantidad importante de cuestiones, todas ellas referentes a Galicia. Entre estos temas podemos destacar discursos sobre el caciquismo, el problema de los transportes, la importación de carnes del Uruguay, el Tratado Comercial con Holanda, los Jurados Mixtos y su repercusión en la agricultura gallega, la Ley de Ordenación del trigo y el maiz, la municipalización de servicios, etc ${ }^{15 b i s}$. Su labor fue llevada de manera tan personal que al final de la legislatura, el 15 de noviembre de 1935, en la defensa los intereses de los pescadores gallegos, no cumple la disciplina de partido y se presenta a una votación nominal. Esta, a pesar de que todos los diputados gallegos votaron a su favor, sin distinción de siglas políticas, fue rechazada con los votos en contra de sus compañeros cedistas de otras zonas por 73 votos contra $38^{16}$. La unión de la derecha gallega predicada por Ruiz del Castillo comenzaba a disgregarse en los numerosos casos concretos que se dieron a lo largo de esta legislatura, al chocar los problemas regionales con la intención general del aparato nacional del partido.

\footnotetext{
Un buen ejemplo del grado de independencia personal a que habia llegado VAzQuEz GuNDiN en sus iniciativas fue el hecho de que durante la discusión en las Cortes de las Actas electorales de la circunscripción coruñesa de febrero de 1936, y ante el fallecimiento de un candidato electo del FP, el nacionalista vasco irujo formuló un voto particular pidiendo que se corrieran las escalas, con lo que se admitiria a VAzOUEz Gundin, absteniéndose su grupo político de apoyar esta iniciativa; en TUSELL, J.; Las elecciones del Frente Popular, Tomo II, Cuadernos para el Diálogo, Madrid, 1971, págs. 178-179.

150is Para ver su línea de defensa de los intereses gallegos en el Parlamento republicano, ver "Vázquez Gundin ou a outra cara da dereita galega da II República"; Analise Empresarial Unipro Editorial, Pontevedra, $n .{ }^{\circ} 26$, maio-agosto, 1997, págs. 73-77.

${ }^{16}$ Diario de Sesiones de las Cortes Generales, Legislatura 1933-1936, págs. 10.559-10.660.
} 
Al margen de los representantes de la Unión Regional de Derechas, el proyecto político de CEDA implicaba también dotar de un mayor protagonismo a los jóvenes dentro de estas formaciones, inmersos como se encontraban en estos momentos en que el ambiente general de todas las organizaciones políticas era la renovación, despreciando todo lo que sonara a tradicional o estático. La URD otorga un papel preponderante a las organizaciones juveniles, convirtiéndose estas en las únicas que continúan con la propaganda local del partido. Es como si los primeros fundadores cedistas, una vez alcanzado el poder, declinaran gustosamente la labor pesada de la difusión del mensaje y se dedicasen a dirigir desde la sombra esta estructura, maniobrando en un campo de ajedrez con unos peones muy móviles y excelentemente disciplinados.

Aunque muchas veces los miembros de las Juventudes de la Unión Regional de Derechas (JURD) se confundieron intencionadamente con los de Falange, y aunque sus acciones eran comunes en la mayoría de las ocasiones al presentar ambos un enemigo común, la percepción real de la sociedad local era que la procedencia de los jóvenes cedistas era bien distinta de los fascistas. Los primeros solian ser hijos de buenas familias, en gran parte integrados en las organizaciones religiosas de la zona, como las Juventudes de Acción Católica o en las distintas cofradías que se encontraban dispersas por todo el país gallego, mientras que las escuadras falangistas se componían en su mayor parte de elementos obreristas y de un considerado bajo nivel social. Solo después del fracaso electoral de febrero de 1936 muchos de los integrantes de las JURD se integraron en Falange, ante lo que el nivel de afiliación falangista se incrementó notablemente.

Y no sólo ellos. Muchos de los integrantes de la URD, vista la «derrota electoral» de febrero de 1936, ante el peligro ya real del marxismo en el gobierno de la nación, pasaron a considerar medidas de fuerza para contrarrestar la situación legal que se había planteado. Los partidos políticos de derechas habían dejado de ser depositarios de la voluntad popular por su incapacidad de entender una votación favorable a la izquierda republicana. Sólo quedaba el recurso a los militares, última expresión de su concepto de nación. Toda esta estructura interna de la URD, creada casi exnovo, se rebelaba contra sus propios principios y ahora era utilizada para planear la trama de un golpe de Estado ${ }^{17}$.

A mediados de junio el Consejo Nacional de las JAP, a través de su Presidente, José Maria PÉREZ DE LABORDA, enviaba las últimas indicaciones a sus miembros: 


\section{EL APARATO DE LA CEDA EN GALICIA}

\subsection{Distribución geográfica e implantación de la URD y las JURD}

El primer objetivo político de la URD era conseguir una mayoría católica y de derechas en el gobierno del Estado. Su segundo propósito era cimentar su organización dentro de unas bases sólidas de actuación, en un entramado bien estructurado de asociaciones. Si bien en el momento inmediatamente anterior a las elecciones de junio de 1931 los Independientes de derechas que se presentaron en listas por las minorías pretendían cierta representación en las Cortes Constituyentes, del modo que fuera, los primeros impulsores de la URD en Galicia recogieron la consigna del Comité Central de Madrid de que en aquellos sitios en los que no se encontrara todavía madura la idea del partido entre la población no se saliera a la lucha electoral más que como Independientes, recogiendo esta experiencia para futuras convocatorias. El resultado de esta intencionada abstención era la creación de un partido político de derechas que ofreciera en su momento el contrapunto ideológico a las nuevas elites republicanas, apartándose desde el primer momento del proceso de configuración del nuevo sistema de representación. Siempre se mantuvieron frente a él, contra una Constitución considerada sectaria.

Pretendian oponer una organización derechista y de masas, circunstancia inaudita hasta el momento en el panorama político español, con la intención de agrupar en torno al catolicismo y la unidad de la patria un voto de rechazo al sistema republicano. Como hemos visto en las páginas anteriores, la difusión del mensaje cedista se origina desde Santiago, gracias a las buenas relaciones existentes entre la organización central de Madrid y determinadas personalidades de la elite local de la ciudad compostelana: Catedráticos, estudiantes universitarios de excelente procedencia social, arquitectos, farmacéuticos, bibliotecarios, etc. Entre los meses de noviembre-diciembre de 1931 y enero-febrero de 1932, la naciente

No preocuparos demasiado del porvenir político, pues los acontecimientos se desarrollarán forzosamente en forma que la transformación de lo que los partidos políticos hayan de transformar, será espontánea y obligada y seguirá siendo fundamento del movimiento nacional de España la masa entusiasta encuadrada en nuestras filas, que es preciso que no se desoriente.

Seguir puntualmente las instrucciones reservadas que en conversaciones particulares os hemos dado para actuar frente a la situación actual de España de anarquia caótica de salvajisme y de indignidad. Trabajad con febril actividad, pues los minutes son en estas circunstancias decisivos. (Subrayado del autor.)

Difundid estas ideas en todos los afiliados.

Un abrazo a todos los compañeros de las J.A.P. y estad todos dispuestos a dar la vida por España: carta fechada el 18 de junio de 1936, Fondo Pérez Ávila, Deputación Provincial de Ourense. 
asociación política que recibe el nombre de Unión Regional de Derechas se extiende por los grandes núcleos de población como A Coruña, Ferrol, Pontevedra, Vigo, Lugo, Ourense, etc.

Si bien éstos fueron los primeros puntos en donde se centró la estrategia propagandística del partido, la realidad es que es en las pequeñas "vilas" con un considerable núcleo de población como Cambados, Muros, Arzúa, Pontedeume, Marín, Porriño, A Guarda, etc, donde se crean asociaciones locales de la URD impulsadas por la actividad interesada de sus propios dirigentes, que se encuentran muy ligados al devenir político de la comunidad local. El carácter espontáneo que rodeó la creación de organizaciones en estas pequeñas "vilas", en los primeros meses de existencia, provoca que en muchas ocasiones se supere a varias de las grandes ciudades gallegas en la actividad demostrada. También nos hace cuestionar el sentido ruralista de la derecha en Galicia, considerando la práctica inexistencia de sociedades plenamente urbanas, y que era expresado desde los primeros años del siglo $x x$ por una presencia activa en el sindicalismo agrario de corte confesional.

Aunque la primera motivación de los dirigentes de la URD fue la expansión hacia los grandes núcleos, buscando un respaldo electoral rápido y cuantioso, la esencia del programa ideológico cedista se encontraba acomodado en medio de las sociedades rurales, en donde la política se medía en cuestiones tangibles y no de programa, se calibraba en las posibilidades de aquellas personas allegadas o conocidas y no en el debate sobre el sistema de gobierno ${ }^{18}$. De hecho, el surgimiento del catolicismo social gallego en la II República debe gran parte de su empuje al voto de la población de estas pequeñas "vilas" con una burocracia media y una burguesía agraria escasamente interesada en las innovaciones.

Muy al contrario de esta situación, en aquellos núcleos con una mayor densidad poblacional, el mensaje de la derecha llegaba a través de otras vías, más indirectas y de menor relación con el emisor. Aquí, el ciudadano de a píe podía elegir entre las opciones ideológicas que se le ofertaban en el escaparate político del momento. La percepción del progreso social en

18 Ésta es la definición que Panebianco hace del «notable":

Es el prototipo del "diletante" de la politica, del que no vive de la política y convierte su posición socioeconómica en una posición política. Constituye el nervio de la dirección en los viejos par. tidos de cuadros. Las previsiones de Weber y Duverger, según las cuales era una figura destinada a desaparecer con el surgimiento del partido de masas, se han confirmado sólo en parte. Lo que ocurre más bien es que el notable continúa conviviendo en los partidos contemporáneos con los otros profesionales de la política; Panebianco, A.; Modelos de partido, Alianza, Madrid, 1990, pág. 439. 
estas ciudades era evidente: se palpaba en el ambiente que el tiempo era rápido, que la división industrial del trabajo se incrementaba y que, del mismo modo, las circunstancias políticas no eran algo tan estático como se había pensado hasta entonces. Si bien en la derecha gallega no existieron muchas voces ajenas al pensamiento tradicional que apostaran de lleno por el republicanismo moderado, el voto en las grandes ciudades comenzaba a cambiar y a pensar de manera individual, sin tener que obligar siempre a elegir entre el blanco o el negro, bueno o malo, aquella mentalidad que la Iglesia católica había potenciado en su discurso ideológico, y que habia extendido a las elites locales.

La derecha que vota a la URD compartirá siempre este planteamiento bipolar de la realidad: o a favor o en contra de la República, sin términos medios. En la práctica diaria votaban por el continuismo en lo político, por lo malo conocido antes que lo bueno por conocer, como lo prueba el hecho de que los representantes cedistas que fueron elegidos en las dos elecciones a las que se presentaron, salvo raras excepciones, daban la sensación de ser herederos directos de las prácticas del sistema parlamentario canovista, yendo a las sesiones de Cortes en contadas ocasiones. En estas, al margen de cierta disciplina de partido en la que se disponía la obligatoriedad de la asistencia en circunstancias puntuales de compromiso político, en las restantes se limitaban a defender los "asuntillos" locales de las zonas y localidades en las que conservaban su influencia electoral. Estos problemas no tenían por que ser necesariamente de carácter político, sino que en esta época en la que se entremezclaban administración y política, eran los abusos locales cometidos en la maquinaria del Estado aquello que se denunciaba en recintos en los que se pretendía dar otra trascendencia al discurso. El voto real despreció sin embargo a aquellos que, como Vázquez Gundín, trabajaron de manera más directa por los intereses de los gallegos, al margen de siglas políticas. Este hecho es una prueba más de la práctica del voto continuista.

Tanto el análisis de las cifras de las elecciones gallegas como las discusiones posteriores en Cortes de estas Actas indican un notable nivel de fraude y manipulación del voto. Esta se dejó sentir muy especialmente en las elecciones de febrero de 1936, decantando el voto hacia las candidaturas de izquierdas en la provincia de A Coruña y hacia los representantes de la derecha en Ourense. De este modo, hay que tener siempre presente el hecho de que la política gallega de este momento tenía claras pervivencias de la práctica electoral de la Restauración, circunstancia que se reafirma con el hecho de la distribución zonal de los candidatos de derechas. En la conjugación de estos dos factores 
de modernidad y tradición se encuentra buena parte del éxito organizativo de la URD ${ }^{19}$.

Aquellos que habian sido elegidos parlamentarios eran figuras escogidas por su respaldo electoral e imagen en una determinada zona o comarca, más que por una elección directa de cada estructura local del partido. La URD gallega a nivel de asociaciones funcionaba de manera paralela a las intenciones de los diputados, a veces llegando a rozarse ambos elementos, pero sin involucrarse dentro de las distintas estructuras locales.

Este carácter externo a la organización que conservaban en parte los representantes gallegos de la derecha en las Cortes españolas no ocultaba el hecho de que su verdadera fuerza se encontraba en los votos obtenidos en cada una de las cuatro circunscripciones electorales. El entramado organizativo del partido se montaba no sólo en función de la importancia e influencia de las distintas élites locales, principal motivo de creación de pequeños comités, sino también desde el potencial que ofrecia desde el exterior de la comunidad local el nombre de CEDA como gran vínculo de relación política. No era lo mismo crear una organización local con el nombre de CEDA, en aquel momento el partido católico por excelencia, que con el de Partido Nacionalista Español, por citar uno de escasa relevancia en cuanto a su expectativa de voto en este territorio.

De todos modos, la dinámica de creación de centros cedistas responde, desde una propaganda realizada con los temas justos y el momento apropiado como resaltar la persecución religiosa desde los sectores republicanos, a una afiliación de dos velocidades. Esto se verifica no tanto en la cantidad de afiliados como en la calidad de los mismos. Desde finales de 1931 hasta 1933, la Unión Regional de Derechas cumple un proceso siempre en línea ascendente de fundación de nuevas sociedades, con el único fin de extender lo más rápidamente posible su nombre por la difícil geografía gallega para conseguir la mayor intención posible de voto. Esto en otras latitudes de la geografía española se podía realizar de un modo mucho más geométrico y concéntrico de difusión de ideologia, fundando

Una fracción por interés no se declara tal, no dice que es un grupo que maniobra por el poder o el botin, por obtener cargos o emolumentos. Puede buscar como cobertura la bandera de la eficacia y del realismo técnico; pero también puede distrazarse con prendas ideológicas. Por otra parte, la ideologia puede ser un camuflaje muy eficaz, tanto en el sentido de que brinda legitimidad a un grupo que aspira al poder en la percepción de sus mismos actores como en el sentido de que el observador no lo puede descubrir con mucha facilidad; SARtori, G.; Partidos y sistemas de partidos, Alianza, Madriđ, 1992, 2. e edición, pág. 103. 
comités en las principales "vilas» y ciudades, e influyendo desde allí hacia los núcleos menos habitados. La peculiar configuración poblacional gallega, con una población relativamente importante pero dispersa, imposibilitaba la realización estricta de la estrategia nacional de extensión del partido. La adaptación al terreno provocó que se redoblaran los esfuerzos físicos de los propagandistas católicos a la hora de celebrar mítines y fundar nuevas asociaciones cedistas en tierras en donde cada valle, cada pequeña montaña, formaba una pequeña comunidad local cerrada en sí misma y dotada de escasas relaciones con el exterior.

Conociendo estas peculiaridades podemos concluir en que la carrera de nuevas fundaciones era vivida en las distintas sociedades locales como la formación de un partido de derechas, confesional y defensor del orden. Se conocía directamente a sus dirigentes, aquellos que en muchos casos se habían destacado como afiliados de los sindicatos católicoagrarios. La actividad que habían demostrado había sido más práctica que teórica, repartiendo revistas técnicas, fomentando la cooperación para la compra y venta de semillas, de maquinaria, de ganado, etc. A la vista de todo ello, poco les importaba en los primeros años a estas elites locales que esta relación con el exterior se llamara CEDA, Unión Regional de Derechas o Partido Radical: la cuestión estaba en aprovechar el momento y el lugar justo.

Sin embargo, cualitativamente la relación cambia cuando la CEDA se sitúa a partir del mes de noviembre de 1933 como el partido más votado en el cómputo general del Estado. Poco a poco y a medida que se va «tocando" poder, se dan a conocer matices dentro de los partidos de derecha. Renovación Española se coloca como el partido de los monárquicos alfonsinos y de la restauración borbónica; el Partido Radical de Lerroux se compromete definitivamente desde posiciones conservadoras con el sistema republicano; la minoritaria Falange comienza a conocerse como el cuerpo de choque de la derecha, etc. Pero por encima de todo ellos, la CEDA - y en Galicia la URD-conservaba aquella posición predominante que le habian dado los primeros votos. En buena parte, fue este carácter de acercamiento al poder que tenía la organización la que querían obtener aquellos grupos que se formaron en Galicia como asociaciones cedistas desde $1934^{20}$.

Este proceso de acercamiento de la estructura del partido cedista a las élites locales tradicionales a partir de la llegada al poder en 1934 es observado también en la organización sevillana por Leandro Álvarez Rey EN La Derecha en la // República, 1931-1936. Universidad-Ayuntamiento de Sevilla, 1993, pág. 451. 
Y es que la llegada al poder tenía que tener algún tipo de consecuencias para el partido. La dinámica de creación de nuevas asociaciones de la URD sufre un cambio. Desde diciembre de 1933 hasta el final del período republicano el ritmo de nuevas fundaciones en Galicia decrece espectacularmente. En la provincia de A Coruña de las 46 que tenemos registradas, 13 pertenecen a este período; en Lugo, 3 de 12; y en Pontevedra, de un total de 43 , solamente 2 se crean entre 1934 y 1936. La única excepción se produce en la provincia de Ourense, la cual no participa del proceso de difusión cedista en las sociedades locales hasta bien entrado el año de 1935, debido a la influencia prácticamente absoluta de Calvo Sotelo entre las elites más influyentes de la derecha.

A pesar de que el ritmo de creación fue bastante inferior al que se venía realizando hasta la fecha, la consolidación se realiza de una manera más sólida, ya que la frenética carrera de fundaciones realizadas entre 1931 y 1933 sólo provocaba la propaganda de un nombre, de unos «apellidos políticos", más que la difusión completa del programa del partido. Desde 1934, la creación de nuevos comités se verá acompañada de la gestión de importantes líderes locales que permanecieron hasta este momento en la sombra, sin saber muy bien cual debía ser el partido político al que debían ofrecer su apoyo. Desde su punto de vista, que mejor relación que la que le daba el partido más votado en Galicia y en el Estado, y que al mismo tiempo había aceptado pocas carteras ministeriales, situándose en una actitud de oposición expectante, intentando jugar con el momento de una nueva convocatoria electoral en la que tenían grandes posibilidades de obtener el mismo poder absoluto de que había gozado la coalición republicano-socialista en el bienio anterior.

Por encima de todo ello, la fallida revuelta socialista de octubre de 1934, y la consiguiente prohibición de partidos de izquierda, desposeyó de los cargos municipales a muchos de los representantes populares gallegos de tendencia republicana o socialista. Que mejor ocasión para ascender políticamente y de manera rápida que colocarse en las gestoras locales que sustituirian a la anterior corporación, desde los dos partidos políticos que dominaban el Ministerio de Gobernación: Partido Radical y CEDA. Ante esta disyuntiva, la elección era clara. El primero de ellos se presentaba como un partido viejo y con escasa renovación en sus filas, adivinándose que ya había dado todo lo que podía a la naciente república. En cambio, el camino que había seguido la Unión Regional de Derechas había sido siempre en línea ascendente desde sus primeros pasos en 1931. Además se intentaba dotar a la organización de una imagen de profunda renovación de la clase política de derechas, cuando menos en lo que se refiere a sus formas externas de actuación. 
Estos cinco años de recorrido y evolución del partido político conservador nos ofrecen un panorama asociativo de importancia considerable, pero que aún conserva grandes diferencias entre las provincias. Así, de las 136 asociaciones cedistas localizadas en toda Galicia, 99 pertenecen a las dos provincias con mayor población, A Coruña y Pontevedra, que además son las que mejor marcan la estructuración interna del partido, dejando las 37 restantes para las dos provincias interiores, Ourense y Lugo. De todas maneras, hay que aclarar que el número resultante de esta división sería mucho mayor si descontamos aquellas asociaciones que se fundan apresuradamente en los últimos meses de 1935, con vistas a una mayor presencia en una campaña electoral que había sido considerada como la "última batalla». Este es el caso de Ourense, en donde poco tenian que ver las distintas siglas: lo verdaderamente importante era la situación en número de votos de los dos bloques políticos mayoritarios.

Donde sí se observa una nítida diferencia en cuanto a que las asociaciones cedistas responden a una organización moderna es en el apartado de creación de las Juventudes. Denominadas en los primeros momentos Juventud de Unión Regional de Derechas (JURD), fueron progresivamente asimiladas a la dinámica estatal con el nombre de Juventudes de Acción Popular (JAP). De las 32 organizaciones juveniles registradas, 22 de ellas pertenecen a las provincias de Pontevedra y Coruña -en las que se encuentran además las únicas 4 organizaciones femeninas--, mientras que de las 10 restantes, 2 pertenecen a la circunscripción lucense y 8 a la de Ourense. En esta última provincia, tenemos que tener en cuenta la excepción de las organizaciones "mayores", ya que sólo una de ellas, concretamente la de la capital provincial, se creó antes de 1935, y desde la fecha de su fundación -1932 - fue incapaz de dotar a la provincia de una estructura más o menos sólida en su área de influencia.

Si bien el estudio de la organización interna de la URD nos permite dar determinadas pautas de actuación, también tenemos que mencionar el hecho de que los integrantes de las organizaciones juveniles no tenían porque ser parecidos a los "flechillas" de la Falange, famosos pocos años más tarde. El límite de edad de 40 años establecido en los reglamentos de estas asociaciones no fomentaba precisamente este espíritu, aunque seguia siendo aquella organización que agrupaba a la población juvenil que se sentía identificada con la Iglesia y el Orden. Pero tampoco su conducta fijaba un límite concreto del partido, ya que siendo definida en un principio como la fuerza encargada de las labores propagandísticas de la CEDA, pocas diferencias podía haber con las acciones realizadas con los miembros de Falange, quizás ciertas diferencias en su extracción social, 
pero sus actuaciones concretas eran muy similares. De hecho, desde el verano de 1935 los miembros de las JAP y Falange ya se encuentran en estrecha relación para la realización de sus acciones contra el bloque juvenil de izquierdas.

\subsection{Organización y jerarquía de poder. La autonomía real de la URD}

La realidad organizativa tenía un claro principio en las organizaciones provinciales. Ello era debido al origen de la propia URD, empeñada en conseguir votos -y por consiguiente, una representación importante de la derecha- de la manera más rápida posible. A todas esas diferencias cuantitativas interprovinciales que hemos visto podemos sumar el hecho cualitativo de que la organización de las dos provincias costeras se pueden caracterizar como un buen ejemplo de estructuración rápida del entramado cedista. Además las organizaciones provinciales de A Coruña y Pontevedra representaban el intento más consolidado de cambiar hacía una concepción más moderna de la política conservadora reclamando el voto de las masas.

Sin embargo las dos organizaciones provinciales del interior, las de Lugo y Ourense, se caracterizan por una directa continuación bajo otras siglas de las mismas personas y aquellas actitudes que regian en la política de sus respectivos territorios desde la Restauración. En las elites locales de la capital de provincia de estas dos últimas circunscripciones se tiene un gran recelo al cambio institucional. Si, existen partidos republicanos y obreros, etc, pero las personas que rigen estos, único vínculo de actuación política en estos momentos, son individuos ya conocidos y de los que se sabe su actuación concreta en su zona de influencia local. Tendrá que llegar la aceptación de la nueva Constitución o a la consideración de que para alcanzar un escaño en Cortes ya no bastaba la presentación nominal de un determinado "cacique" o personaje relevante sin un respaldo de siglas detrás, para que los parámetros mentales del conservadurismo local de estas sociedades acepten, comprendan y muestren un proceso de adaptación dentro de la nueva situación.

Sin embargo, la organización interna de la URD seguia pautas semejantes a los restantes partidos. Sus comités se dividian en Parroquiales, Locales y Provinciales. En los primeros la influencia de la sociedad local era predominante, limitándose a aprobar las disposiciones que se adoptaban en los comités locales del municipio en cuestión. Estas últimas eran a su vez difundidas desde el comité provincial que llegaba desde Madrid, vía Santiago, como órgano de relación con el comité central. En Galicia solo hay 
una excepción a este tipo de comportamiento. La organización de la ciudad compostelana, en las elecciones de febrero de 1936, obtuvo el grado de comité provincial al dividirse la circunscripción coruñesa en dos áreas de influencia con rango de dirección: las comarcas del norte con sede en la capital de la provincia, A Coruña, y las del sur hasta el límite provincial con la de Pontevedra, que tenía la dirección en Santiago, y en la que también se aprovechaba su gran infraestructura en materia de propaganda.

En muy contadas ocasiones, los comités locales discutían en sus reuniones cuestiones de índole particular. En parte porque la dinámica política durante la II República acercaba las cuestiones de Estado a las sociedades locales y trasladaba la bipolarización y división de siglas de los oradores parlamentarios a sus representantes en las "vilas" y aldeas gallegas, estableciendo como lugar de debate aquellos lugares de sociabilidad como el atrio de la Iglesia o la taberna.

Como se puede adivinar después de leer las páginas anteriores existía una gran disciplina en la organización interna de la URD gallega respecto a sus órganos de base, y por consiguiente un reparto casi perfecto de las esferas de poder: local, provincial, regional... Únicamente hemos localizado un par de casos concretos en el que el Comité Central de Madrid tuvo que tomar cartas en el asunto para que se siguieran sus instrucciones. Estas situaciones excepcionales tenía que producirse precisamente en aquel hecho que más discusiones y problemas planteaba en los Comités Provinciales: la elección de los candidatos que se presentaban a elecciones a Cortes.

El Presidente del Comité Provincial de Lugo, diputado a Cortes en 1933 y ex-alcalde de la capital, Ángel López Pérez, se encontró con que cuando recibió los nombres de los candidatos a las elecciones de febrero de 1936 en los últimos días de ese mes de enero se encontraba excluido de dicha candidatura en beneficio del gran "amañador» electoral del primer tercio del siglo $x x$ en la provincia, José Benito Pardo. Este se había adherido a la CEDA en los meses inmediatamente anteriores a estas elecciones y era conocido a escala nacional por sus habilidades en el manejo de las urnas. El 23 de enero se celebra una Asamblea en el local de la CEDA lucense en el que el Presidente Ángel López Pérez manifiesta textualmente que:

...aunque la Sociedad está afiliada a la CEDA, no están dispuestos a acatar la candidatura impuesta por el Sr. Gil Robles, debido a que en ella vienen encasillados hombres que tratan de destruir esta Sociedad, que no son de derechas y sólo vienen con objeto de monopolizar la política de esta provincia ... ${ }^{21}$.

Archivo Histórico Provincial de Lugo, Fondo Gobierno Civil, legajo 460. 
La decisión final fue tomada unilateralmente por el propio Gil Robles, quién dias antes se había desplazado de una gira de mítines que realizaba por Galicia, hacia Chantada con el objetivo de mantener una reunión con Saco Rivera. Ante la imposibilidad de obligar a la mayoría del comité provincial a seguirle adopta una actitud drástica, y releva al Presidente de su cargo obligando a Manuel Portela, que ostentaba la presidencia en la Juventud de Derechas y Agrarios a aceptar su sustitución. Esta nueva dirección legitimaría la candidatura del Comité Central tan sólo una semana después, el 31 de enero ${ }^{22}$.

Similar situación se planteó en Ourense en el proceso de selección de candidatos de esta misma elección, al colocar desde la directiva nacional en los tres puestos a que tenía derecho la CEDA por la circunscripción a candidatos vinculados al Partido Radical bajo las siglas cedistas ${ }^{23}$. En uno y otro caso el poder real era ejercido por Madrid, y no por la URD, en teoría una organización con notables grados de autonomía. De este modo tan expeditivo se solventaban los problemas de indisciplina interna en la CEDA gallega, con la única decisión del Comité Central.

$Y$ es que a excepción de las consignas propagandísticas difundidas en los núcleos más poblados de Galicia, la relación entre la organización central de la CEDA y la URD gallega siempre estuvo caracterizada por una escasa horizontabilidad en sus relaciones. Su vínculo relacional se encontraba definido por una línea absolutamente vertical que tenía en su piso superior a la dirección compostelana y los diputados en Cortes, mientras que en sus niveles inferiores estaban los distintos comités locales ${ }^{24}$. Las decisiones eran tomadas íntegramente por la cúpula nacional del partido siguiendo este esquema:

- Las instrucciones y consignas generales se enviaban desde Madrid a la sede central de coordinación gallega en Santiago.

- Desde esta ciudad se difundía la información recibida y se enviaba a las grandes ciudades gallegas. Estas tenían también a su cargo

\section{A.H.P. Lugo, F.G.C., legajo 461.}

A partir de 1935 se constata la existencia de protestas reiteradas de los sectores de JAP por la paulatina inserción de estos hombres como dirigentes del partido cedista, como se comprueba en el Fondo Pérez Ávila. Deputación Provincial de Ourense.

${ }^{24}$ La relación entre los dirigentes del partido (a nivel nacional) y el grupo parlamentario, constituye sólo uno de los elementos a tener en cuenta. El segundo de esos aspectos es la estructura periférica: es decir, si la estructura intermedia (regional) es fuerte o débil. Si es fuerte... los lideres regionales constituyen un elemento capaz de equilibrar el poder del grupo parlamentario. Si, por el contrario, es débil el grupo parlamentario... carece de contrapesos institucionales y aparece por ello como dominante; PANEBIANCO, A.; op. cit., pág. 32.5 
sus respectivas demarcaciones zonales de actuación, con una autonomía de movimientos muy limitada (A Coruña, Lugo, Vigo, Pontevedra, Ourense).

- Desde aquí se designaban y nombraban los integrantes y oradores de los distintos mítines o actos para sus respectivas áreas de influencia, o aquellos en donde su discurso pudiera encajar mejor con la situación concreta de la comarca. Las asociaciones de las localidades donde tendrian lugar estos actos propagandísticos y mítines en realidad contaban muy poco, y tenían que atenerse a las posibilidades físicas de los oradores más solicitados.

Resulta curioso destacar como la jerarquía de actuación se cumple estrictamente, delegando ciertos poderes en los niveles intermedios, como en el caso concreto de las elecciones con la celebración de mítines, pero sin perder nunca de vista que la decisión final, como ocurrió en la práctica en los casos ya relatados de Ourense y Lugo, la tiene Madrid. Si bien en un principio, la intencionalidad manifiesta de los fundadores de la Unión Regional de Derechas era dotar de cierto sentido regionalista a sus aspiraciones como partido confesional de derechas -y no en vano el partido se denominó como "Regional»-, la realidad final era bien distinta.

A excepción de las comunidades de Cataluña y Euzkadi, que contemplan su articulación política desde una perspectiva distinta en la que entran en juego los partidos nacionalistas, la otra comunidad histórica reconocida y que consigue la celebración de un referendum de autonomía con resultado favorable durante la II República fue Galicia. Sin embargo, el peso de la propaganda de este Estatuto, llevado a la aprobación final de las Cortes españolas precisamente la misma semana en que se produjo el golpe de Estado encabezado por el General Franco, lo llevó integramente el Partido Galeguista como compromiso en la coalición gallega del Frente Popular. Este partido fue adoptando a medida que avanzaba la República una actitud cada vez más de izquierdas, sin tener un partido de derechas que diera forma a este intento. Este partido deberia haber sido la URD, que junto a la Derecha Regional Valenciana - estudiada por Rafael Valls ${ }^{25}$-, son los dos únicos partidos que desde el interior de CEDA intentan enganchar la atractiva relación que existía para sus potenciales votantes de poner en común las ideas de regionalismo y catolicismo, con un profundo recuerdo del ideario del Tradicionalismo Carlista.

25 R. Valls, La Derecha Regional Valenciana (1930-1936), Alfons el Magnanim, Valencia, 1992, y El partit católic, Universitat de Valencia, 1993. 
Muy al contrario la URD fue el único partido político consolidado en Galicia que se abstuvo de asistir a las distintas reuniones preparatorias que se celebraron para la redacción del texto autonómico. Aquellos dirigentes del partido que asistieron a las reuniones preparatorias de A Coruña y Santiago lo fueron expresamente a título individual, con lo que la URD negaba implícitamente con su práctica política sus teóricas aspiraciones regionalistas ${ }^{26}$. Incluso existió un hecho tremendamente clarificador en este apartado, ya que a finales de 1932 se pretendió crear dentro del propio partido, y a través de destacadas personalidades de la organización compostelana que conservaban relaciones dentro de los círculos regionalistas del primer tercio de siglo, un Grupo Galleguista de Derechas. Éste se presentó a la prensa, pero después de cumplir un primer objetivo propagandístico, fue boicoteado por la propia jerarquía de la URD, desapareciendo de la escena política ${ }^{27}$.

La realidad fue que en una primera idea política la Unión Regional de Derechas pretendía autodotarse de cierto mensaje regionalista, aunque siempre poniendo como límite aquellos puntos que la ortodoxia del pensamiento conservador católico permitía. Eran conscientes de las simpatías que acarrearía y de la buena imagen que un mensaje de afirmación "gallega" supondría para la naciente organización. Pero después de los primeros momentos de difusión de la propaganda la organización central de Madrid basó su estrategia en unificar - a partir de ella- los distintos grupos afectos a Acción Popular, y más tarde, a la Confederación Española de Derechas Autónomas. Esta estrategia unificadora restó impulsos a los intentos particularistas de cada asociación regional. Mucho menos se podía consentir la difusión de un regionalismo gallego de derechas desde la URD. Esto fue un ejemplo de lo que la difusión general de pocas ideas pero muy concretas en la CEDA trajo respecto a las pretensiones iniciales de ciertos fundadores: la calidad dejó paso a la cantidad, al interés común del partido. Esta circunstancia se unió a la posibilidad de un proyecto mayoritario a escala nacional de derechas, que se definia explícitamente por su confesionalidad y su apego al orden, sin distinciones, un bloque homogéneo y sin fisuras.

La insistencia del discurso de la URD de los primeros años de la República en presentarnos una asociación política que se creaba por la ac-

26. Estas reuniones se verificaron en medio de un clima de gran debate y aceleramiento en su discusión, según el testimonio en notas manuscritas del ex-alcalde de A Coruña Manuel Casás; Caja 92, Archivo de la Real Academia Galega.

E.I.G. del 17 de diciembre de 1932. 
ción y el reagrupamiento espontáneo de los sectores conservadores de las distintas sociedades locales no se cumple más que en una pequeña parte. La orientación de la estructuración del partido no se realiza de abajo a arriba, sino al contrario, es decir, con un esquema jerárquico con los siguientes puntos de enlace y con una dirección prácticamente unívoca: Madrid-Santiago-comité de capital de provincia-comité de zona-organizaciones locales.

El único momento en el que esta relación se invierte y las influencias locales se convierten en determinantes es durante el período pre-electoral. Es en este momento cuando todas las candidaturas y listas que se presentan por las cuatro circunscripciones necesitan el apoyo de las redes clientelares locales, ya que aunque no se pretenda manipular el voto, por lo menos el control de las influencias caciquiles no incidirá en sentido contrario. En Galicia el peso de las organizaciones locales en la configuración de las candidaturas de derechas para las elecciones de febrero de 1936 será muy importante, precisamente por las especiales características de la votación ${ }^{28}$.

Los poco más de cinco años que duró el régimen republicano, unido al proceso de aceleración política de este período, impidió la instalación con garantías de futuro de la estructura de partido de la URD. Sin embargo, cumplió en parte los objetivos con los que se había creado relativos a la defensa de la Iglesia y del orden establecido. Esta era la intención real de sus bases cuando solicitaban el apoyo a la CEDA gallega. Sus propósitos políticos quedaban cubiertos tras estas siglas ${ }^{29}$.

28 Característica que TUSELL amplia para toda la derecha española; en TUSEll, J.; Las elecciones del Frente Popular, op. cit., Tomo i, pág. 43.

Sin un minimo de distanciamiento entre la clase política y su pueblo soberano, aquella no podria conservar su margen de acción, por lo que, a largo plazo, no podria satisfacer las aspiraciones de sus mandantes; KLAUS VON BEYME; op. cit., pág. 25. 